\title{
Motivating Students to Learn AI Through Social Networking Sites: A Case Study in Hong Kong
}

\author{
Davy Tsz Kit Ng and Samuel Kai Wah Chu \\ University of Hong Kong
}

\begin{abstract}
In Hong Kong, after-school activities have long been used to foster friendships and to allow students to pursue their interests in an informal setting. This case study reports on a three-phase action research process in which information technology teachers delivered after-school activities focused on artificial intelligence during the COVID-19 transition to remote learning. Using semistructured interviews, a motivational questionnaire, and lesson observations, this study describes how extracurricular activities were delivered online using social networking sites and how students perceived the new experience. Our results suggest that, in order to deploy meaningful activities via social media, teachers need to build collaborative environments that facilitate social engagement among students. These findings have implications for new practices in social media and other blended technologies, and can help students strike a healthy balance between their academic and non-academic life during this challenging period.
\end{abstract}

Keywords: COVID-19, coronavirus, artificial intelligence learning, extracurricular activities, social networking sites, gamification, secondary school

Ng, T.K. \& Chu, K.W. (2021). Motivating students to learn AI through social networking sites: A case study in Hong Kong. Online Learning, 25(1), 195-208. https://doi.org/10.24059/olj.v25i1.2454

\section{Motivating Students to Learn AI Through Social Networking Sites: A Case Study in Hong Kong}

School-related delinquencies such as disengagement, skipping classes, and cheating are not uncommon among students (Newton, 2015; Shen, 2020). Under normal circumstances, extracurricular activities (ECAs) play a prominent role in addressing these problems by helping students strike a balance between their academic performance and social well-being, thus lessening counterproductive behaviours (Zaff et al., 2003). Research on ECAs suggest they can positively influence students' well-being and academic outcomes by enhancing social development (Snellman et al., 2015); contributing to a sense of belonging in the community (Vieno et al., 2005); improving learning attitudes, participation in learning activities, and school attendance (Gifford \& Dean, 1990; Thouin et al., 2020); establishing supportive social networks of teachers and 
classmates (Mahoney, 2014); and building students' civic skills and practical abilities, such as leadership and project management (Awuah, Agyepong \& Kwarase, 2020).

However, the COVD-19 pandemic has suspended school and school-based activities across the globe. In Hong Kong, face-to-face classes were suspended for four months, beginning on 3 February 2020 ( $\mathrm{Ng}$ et al., 2020). Face-to-face after-school activities were similarly suspended. School-related delinquencies remained a potential problem during this period, in that the prolonged suspension of both classes and after-school activities threaten to worsen social isolation and thus pose a risk to students' developmental and social health (Crawford et al., 2020; Kong, 2020; McAleer, 2020).

Before the outbreak, the first author, an information technology (IT) teacher at a secondary school in Hong Kong, had designed eight sessions on Artificial Intelligence (AI) that involved hands-on programming $(\mathrm{Ng}, 2021)$. These were originally meant to be delivered as after-school ECAs for junior secondary students. With the advent of COVID-19, the activities were quickly redesigned for distance learning using a social networking site (SNS), and were launched in late February. Based on student feedback, the activities were substantially re-designed twice more during the Spring 2020 semester. This case study reports on the process of initial redesign and the subsequent cycles of student feedback and redesign, and provides practical implications for the design of online ECAs.

\section{Cycles of Course Redesign}

This action research project was conducted in three phases. Each phase represented a ministudy, including a review of past evidence, ensuing program redesign, data collection regarding the redesign, and analysis of those data, which provided evidence for the next phase and opportunity for improvement (Avison, Baskerville \& Myers, 2001; Creswell, 2014). Within each phase, data collection consisted of semi-structured interviews, motivational questionnaires (Lee, Yin \& Zhang, 2010), and lesson observations; analyses created rich descriptions which helped us understand which components of the course were working well and which components needed improvement in order to better meet the needs of struggling students (Stringer, 2008; Efron \& Ravid, 2019).

In the first phase, we converted the existing face-to-face curriculum to asynchronous online modules delivered on a social networking site; in the second phase, we added gamified tasks; and in the third phase, we added live synchronous online sessions. Table 1 provides an overview of the three phases. In subsequent sections, we provide more detail for each phase, including past evidence which informed that phase of course redesign, key redesign features, data collection and analysis, and practical implications for the next phase of redesign. 


\section{Table 1}

Learning Activities in the Online AI ECAs

\begin{tabular}{ll}
$\begin{array}{l}\text { Action } \\
\text { changes }\end{array}$ & $\begin{array}{l}\text { First phase } \\
\text { (24 Feb-20 Mar) }\end{array}$ \\
\hline Pedagogy & Asynchronous learning via SNS \\
Teacher & $\begin{array}{l}\text { Set up modules on the SNS to } \\
\text { behaviour } \\
\end{array}$ \\
& $\begin{array}{l}\text { Prepare learning tasks delivered } \\
\text { to students through Edmodo } \\
\text { (e.g. a video for each unit, some } \\
\text { polls, an e-quiz and three open- } \\
\text { ended discussion questions). }\end{array}$
\end{tabular}

Student behaviour

Complete three online tasks after watching the educational videos.

Communicate with other participants using the Facebooklike features (e.g. 'likes', sharing content) and discussion forums.

$\begin{array}{ll}\begin{array}{ll}\text { Estimated } \\ \text { time }\end{array} & \begin{array}{l}1 \text { hour/week for videos and } 1 \\ \text { hour/week for three online } \\ \text { tasks. }\end{array}\end{array}$

Learning Task 1: Polls (True-or-false Tasks questions)

Task 2: E-quiz (MC questions)

Task 3: Open-ended discussion questions:

In our daily life, give some examples of AI applications, and suggest which technologies (e.g. facial, voice recognition) they belong to.

Do you think the AI applications has more advantages than disadvantages, or does the disadvantages outweigh the advantages?

\section{Second phase (20 Mar-20 Apr)}

Third phase (20 Apr-20 May)

Gamification via SNS

Share four gamified tasks via educational posts through Edmodo.

Scaffold students' understanding of AI concepts through engaging gamified tasks and simulations. Machine Learning
Synchronous learning

Conduct three real-time sessions using a video conferencing platform, Google Meet:

Session 1: AI Fundamentals,

Session 2: Neural Network I/ II, Decision Tree Classifier

Session 3: Deep Learning, Facial Recognition, Eye Tracking

Complete four gamified tasks and showcase their work and learning journey via shared posts.

Complete three face-to-face activities.

Co-construct knowledge by recapturing the key AI concepts, making enquiries and participating in discussions through Google Meet.

1 hour/week for videos and 1 hour/week for four games.

1 hour/week for videoconferencing sessions and 1 hour/week to continue with their online tasks.

Game 1: Code.org 'Ocean' To Activity 1: Recapturing the train a model to identify objects concepts (To highlight the key that belong in water. content knowledge of each unit)

Game 2: A Van-Gogh-style Mona Lisa (image stylizer) To stylise a picture with a predefined famous painting style.

Game 3: AI Model Trainer To train a model to classify two objects or colours.

Game 4: Face AI To find your Activity 2: Machine-learning demonstrations (To scaffold students' AI learning through simulations and demonstrations)

Activity 3: Mini conference to share students' gamified work on a face-to-face online basis (To present student work to other classmates.) celebrity look-alike and estimate your age by analysing your face. 


\section{First-phase Implementation Beginning in Mid-February}

To quickly adapt the existing curriculum to a remote context, we selected the social networking site (SNS) Edmodo as the delivery platform. Edmodo is a platform that resembles Facebook; it connects students to create a collaborative learning environment, allowing them to share learning resources such as gamified tasks, videos, and infographics (Thongmak, 2013; Holland \& Muilenburg, 2011). Such SNS platforms can supplement students' traditional learning by affording students learner-centred opportunities to share information, exchange knowledge, and build collectively on each other's intelligence (Chu et al., 2017). These platforms may extend students' learning environment outside the classroom, enable students to co-construct knowledge without constraints of time and space, and thereby serve as an effective learning tool for STEM (science, technology, engineering, and mathematics) areas (e.g. Evans, Won \& Drape, 2014; Greenhow, Robelia \& Hughes, 2009; Holland \& Muilenburg, 2011; Li et al., 2020; Won et al., 2017).

With support from a local technology company, the programme was redesigned to form seven online modules delivered via Edmodo, covering the following topics: (a) AI fundamentals, (b) machine learning, (c) neural network I/II, (d) decision tree classifier, (e) deep learning, (f) facial recognition, and (g) eye tracking. Each module included a pre-recorded educational video that gave students direct instruction about the AI concept. After watching each video, students were expected to complete asynchronous learning tasks and interact with other classmates on Edmodo via shareable posts. Students could access self-paced resources (e.g. videos, polls, and quizzes) regardless of time and space constraints (Garrison, 2003). As an illustration, Figure 1 shows a screenshot from a video which explains the difference between machine learning and deep learning.

\section{Figure 1}

Screenshot of a Video Explaining the Difference Between Machine Learning and Deep Learning.

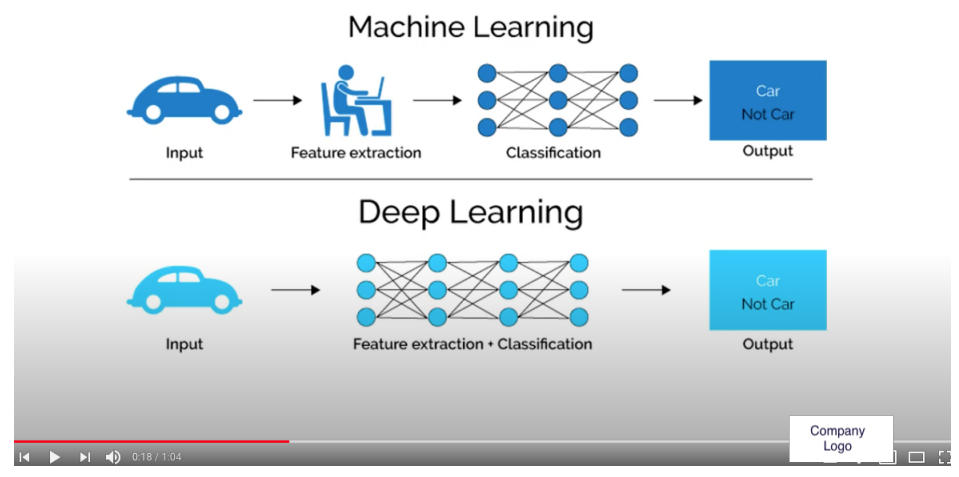

The redesigned curriculum launched in mid-February with $\mathrm{N}=98$ students from a local secondary school, who ranged in age from 12 to 15 . The author delivered all content online once a week, while two IT teachers from his school provided feedback for students, shared educational posts in the SNS, and assisted in synchronous sessions.

We expected that students would benefit from the flexibility of using social networking sites for extra-curricular learning; however, in the first two weeks of the program, only 12 out of 
98 participants became active and spent more than one hour per week on the platform. This behaviour prompted us to conduct interviews with the students to identify their needs and ways that we could further improve our blended practices.

Semi-structured interviews were conducted with $\mathrm{N}=12$ active participants through live online video meetings. Questions focused on why students joined this activity, what features they liked in Edmodo and, most importantly, how students would improve the course. Some students said the ECA helped alleviate the boredom they were feeling as a result of the suspension of classes, and they appreciated the social nature of the SNS. For example, students commented that "I can know more friends who have common interests" or "I can socialise with my friends through commenting, giving 'likes' and sharing posts." However, eight of them said they found the AI concepts difficult to understand and suggested that they would like more teacher support and learning aids. They also suggested that more interesting content be added to sustain their motivation, with several mentioning "simulations" and "games" specifically. For example, one student commented, "It's hard for me to concentrate alone. It would be better if we have some interactive content such as simulations and games."

\section{Second-phase Implementation Beginning in Mid-March}

After identifying the challenges in the first phase, we decided to adopt gamification strategies to sustain students' motivation to engage with the online community. Gamification has previously been found to effectively stimulate student motivation, learner engagement and social influence (Li \& Chu, 2020). Zainuddin et. al. (2020) analysed the impact of gamification on students' achievement and attitudes in a systematic review of 46 research papers published between 2016 and 2019. They concluded that the gamification of learning activities significantly improved students' academic achievement (e.g. Çakıroglu et al., 2017; De-Marcos et al., 2016); intrinsic motivation in terms of fun, enjoyment, usefulness, meaningfulness and attractiveness (e.g. Aldemir et al., 2018, Özdener, 2018); and students' engagement in terms of behaviour, emotion and cognition (e.g. Çakıroglu et al., 2017; da Rocha Seixas et al., 2016). In AI learning, prior studies suggested that low-cost gamifications such as robotic toolkits, web-based machinelearning simulators, and coding games can be used to effectively extend children's learning experience (Fernandes, 2015; Williams, Park, Oh \& Breazeal, 2019; Yoon \& Kim, 2015). Such hands-on tools can offer students playful experiences that foster their motivation and involvement to scaffold basic concepts in machine learning, training data, and the identification of examples of AI in our everyday lives (Ali et al., 2019; Llorens-Largo et al., 2016; Parsons \& Sklar, 2004; Bayliss, 2012).

To provide gamified content, we identified, curated, and shared links to AI modelling games that were freely available online. For example, Figure 2 shows a screenshot of a student's submission in response to an "AI for Oceans" activity. The student built a machine-learning model that analysed a set of images (e.g. trash and fish) and classified them based on features extraction and patterns recognition. After completing gamified tasks, students shared their work on Edmodo to encourage other classmates to play and make their own models. 


\section{Figure 2}

Example Student Social Media Post in Response to an "AI for Oceans” Gamified Activity

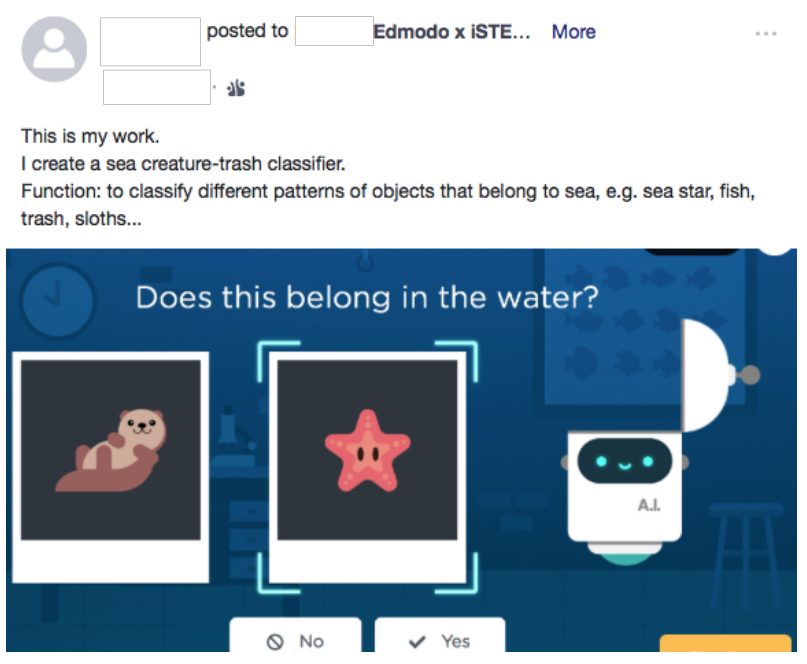

To help us understand students' perceptions of the extracurricular activities in the second phase of the programme, we invited the participants to complete a version of the Motivated Strategies for Learning Questionnaire (MSLQ, Pintrich et al., 1994), a well-established and broadly used instrument for measuring students' motivational beliefs and learning strategies in self-regulated learning which has been revised and validated for junior secondary students in Hong Kong (MSLQ-RCV, Lee, Yin \& Zhang, 2010). We further revised the questionnaire for our particular context; see the Appendix for details. On the 5-point Likert scales, students had mildly positive scores on intrinsic motivation $(M=3.28, S D=0.84)$, self-efficacy $(M=3.11, S D=0.76)$, learning strategy $(M=3.14, S D=0.81)$ and self-regulation $(M=3.15, S D=0.71)$. However, students' overall satisfaction with the programme was low $(M=2.44, S D=0.70)$. These results indicated to us that most students appreciated the opportunity to learn about AI, but that further improvements to the programme were still necessary. Using another round of face-to-face online interviews with the 12 students in the first-phase implementation, we asked students how we could further improve our online ECAs to meet their needs. Six students commented that we needed to provide activities with different levels of difficulty and more detailed instructions on how to complete laboratory exercises. In an online poll, 51\% expressed the need for more social interaction among students and teachers via synchronous sessions. In response to students' feedback about the second phase, we decided to use Google Meet, a web-conferencing tool, to support synchronous sessions and further stimulate students' AI learning in the third phase.

\section{Third-phase Implementation Beginning in Mid-April}

In online and blended learning contexts, social presence has been found to be necessary for building successful communities of enquiry in which students can share ideas, receive helpful feedback, improve critical thinking and engage in co-construction tasks (Brown et al., 2016; Ng et al., 2020). Through media-rich, real-time communication tools such as video conferencing and instant messaging software, synchronous activities encourage students to interact with one another in online educational settings (Bower et al., 2013; Bell, Sawaya \& Cain, 2014). To incorporate these opportunities for our students, three one-hour synchronous sessions were conducted over 
Google Meet in the third phase of the programme. The synchronous sessions provided teachers with a platform for developing an online classroom routine that encouraged students to engage with the material regularly. During the synchronous sessions, we highlighted the focus of each learning unit, conducted discussions, demonstrated tasks, and advised students to adopt specific self-regulation practices (e.g. time management, encouraging other classmates to share one's work) to help themselves and one another stay active in the online AI ECA programme.

To understand whether the addition of the synchronous sessions improved the student experience, the motivational questionnaire was re-administered a second time; as shown in Table 2 , paired-samples $t$ tests indicated a significant improvement in intrinsic motivation, learning strategy, self-regulation, overall satisfaction, and student quiz scores. Additional feedback was collected from the 12 students again in a third round of interviews at the end of the program. Students expressed the opinion that the synchronous sessions had the advantage of allowing realtime teacher-student interaction, which they said enhanced their motivation more than the asynchronous activities of content-sharing and self-paced tasks conducted through the SNS. For example, one student commented:

AI concepts are not easy to understand. The Google Meet sessions give us opportunities to discuss, play and interact online with classmates and teachers. Moreover, I stay at home almost every day. Some face-to-face teaching can make learning more interactive, instead of merely doing the self-paced games, content, and tasks in the SNS.

Despite these advantages, however, students claimed in their interviews that they still preferred traditional face-to-face after-school activities over online or blended ECAs. In elaborating on the limitations of online learning, they cited activities that were more difficult to do online, such as making physical products (e.g. robotics, electronics), and planning and organising student-led activities (e.g. student council, sports games).

\section{Table 2}

Measurements Before and After Attending Synchronous Sessions ( $n=98)$

\begin{tabular}{lrll} 
& $\begin{array}{l}\mathbf{2}^{\text {nd }} \text { phase } \\
\text { Mean (SE) }\end{array}$ & $\begin{array}{l}\mathbf{3}^{\text {rd }} \text { phase } \\
\text { Mean (SE) }\end{array}$ & Paired t-test \\
\hline MSLQ Scales & & & \\
Intrinsic motivation & $3.28(0.09)$ & $3.73(0.07)$ & $2.97^{*}$ \\
Learning strategy & $3.14(0.08)$ & $3.62(0.07)$ & $3.24^{*}$ \\
Self-regulation & $3.15(0.07)$ & $3.61(0.07)$ & $3.14^{*}$ \\
Overall satisfaction & $2.44(0.08)$ & $3.42(0.08)$ & $5.83^{*}$ \\
Quiz scores (full marks: 12$) 9.84(0.27)$ & $10.98(0.22)$ & $2.35^{*}$ \\
\hline
\end{tabular}




\section{Conclusion}

Students' satisfaction and performance in the third phase of the online ECA suggested that our approach-including gamified tasks, the use of an SNS and synchronous sessions-was effective during the suspension of face-to-face classes. The approach helped secondary students to connect with other classmates which may, in turn, sustain their interest in developing IT hobbies, skills, and knowledge. A similar combination of asynchronous and synchronous activities could be adapted for ECAs in other disciplines. Providing ECAs amid school closures helps students strike a balance between their academic life and personal well-being.

This approach is also worth exploring as a mode of delivering ECAs even after face-toface classes resume. While students in our case study still expressed a preference for traditional face-to-face activities, an approach which blends online and face-to-face elements could potentially provide multiple advantages. With support from SNSs, a blended approach could encourage students to co-construct knowledge, showcase their learning journey, and enrich the student learning experience outside the classroom.

One of the limitations of this study is that it focused on students' perceptions of the new experience of online ECAs, their learning motivation, and their achievement based on online quizzes. Further research needs to be conducted to investigate whether online or blended ECAs are as effective as face-to-face ECAs at enhancing academic achievement, reducing threats to students' well-being, and addressing the social needs and health of the most vulnerable children. Moreover, other useful strategies, tools and activities for instructional design should be explored in future work. 


\section{References}

Aldemir, T., Celik, B., \& Kaplan, G. (2018). A qualitative investigation of student perceptions of game elements in a gamified course. Computers in Human Behavior, 78, 235-254. https://doi.org/10.1016/j.chb.2017.10.001.

Ali, S., Payne, B. H., Williams, R., Park, H. W., \& Breazeal, C. (2019). Constructionism, Ethics, and Creativity: Developing Primary and Middle School Artificial Intelligence Education. In International Workshop on Education in Artificial Intelligence K-12 (EDUAI'19), 1-4.

Avison, D., Baskerville, R., \& Myers, M. (2001). Controlling action research projects. Information Technology \& People, 14(1), 28-45. http://dx.doi.org.eproxy.lib.hku.hk/10.1108/09593840110384762.

Awuah, R., Agyepong, S., \& Kwarase, P. (2020). Leadership education through extracurricular civic engagement. Partnerships: A Journal of Service-Learning and Civic Engagement, $11(1), 257-274$.

Balyer, A., \& Gunduz, Y. (2012). Effects of structured extracurricular facilities on students' academic and social development. Procedia-Social and Behavioral Sciences, 46, 48034807.

Bayliss, J. D. (2012, September). Teaching game AI through Minecraft mods. In 2012 IEEE International Games Innovation Conference (pp. 1-4). IEEE.

Bell, J., Sawaya, S., \& Cain, W. (2014). Synchromodal classes: Designing for shared learning experiences between face to face and online students. International Journal of Designs for Learning, 5(1), 68-82.

Brooks, B. A., Floyd, F., Robins, D. L., \& Chan, W. Y. (2015). Extracurricular activities and the development of social skills in children with intellectual and specific learning disabilities. Journal of Intellectual Disability Research, 59(7), 678-687.

Bower, M., Kenney, J., Dalgarno, B., \& Kennedy, G. E. (2013). Blended synchronous learning: Patterns and principles for simultaneously engaging co-located and distributed learners. In ASCILITE-Australian Society for Computers in Learning in Tertiary Education Annual Conference (pp. 92-102). Australasian Society for Computers in Learning in Tertiary Education.

Brown, M. G. (2016). Blended instructional practice: A review of the empirical literature on instructors' adoption and use of online tools in face-to-face teaching. The Internet and Higher Education, 31, 1-10.

Çakıroglu, U., Başıbuyuk, B., Guler, M., Atabay, M., \& Memiş, B. Y. (2017). Gamifying an ICT course: Influences on engagement and academic performance. Computers in Human Behavior, 69, 98-107. https://doi.org/10.1016/j.chb.2016.12.018.

Chu, S.K.W., Capio, C.M., van Aalst, J.C.W., and Cheng, E.W.L. (2017). Evaluating the use of a social media tool for collaborative group writing of secondary school students in Hong Kong. Computers \& Education, 110(7), 170-180.

Crawford, J., Butler-Henderson, K., Rudolph, J., Malkawi, B., Glowatz, M., Burton, R., \& Lam, S. (2020). COVID-19: 20 countries' higher education intra-period digital pedagogy responses. Journal of Applied Learning and Teaching, 3(1), 1-20. 
Creswell, J. W. (2014). Educational research: Planning, conducting, and evaluating quantitative and qualitative research. Frenchs Forest.

De-Marcos, L., Garcia-Lopez, E., \& Garcia-Cabot, A. (2016). On the effectiveness of game-like and social approaches in learning: Comparing educational gaming, gamification \& social networking. Computers \& Education, 95, 99-113. https://doi.org/10.1016/j.compedu.2015.12.008.

Evans, M. A., Won, S. G., \& Drape, T. (2014). Interest-driven STEM learning among youth through a social networking site. International Journal of Social Media and Interactive Learning Environments, 2(1), 3-20.

Fernandes, M. A. (2016). Problem-based learning applied to the artificial intelligence course. Computer Applications in Engineering Education, 24(3), 388-399.

Garrison, D. R. (2003). Cognitive presence for effective asynchronous online learning: The role of reflective inquiry, self-direction and metacognition. Elements of quality online education: Practice and direction, 4(1), 47-58.

Gifford, V. D., \& Dean, M. M. (1990). Differences in extracurricular activity participation, achievement, and attitudes toward school between ninth-grade students attending junior high school and those attending senior high school. Adolescence, 25(100), 799.

Greenhow, C., Robelia, B., \& Hughes, J. E. (2009). Learning, teaching and scholarship in a digital age: Web 2.0 and classroom research: What path should we take now? Educational Researcher, 38(4), 246-259. https://doi.org/10.3102/0013189x09336671.

Holland, C., \& Muilenburg, L. (2011, March). Supporting student collaboration: Edmodo in the classroom. In Society for Information Technology \& Teacher Education International Conference (pp. 3232-3236). Association for the Advancement of Computing in Education (AACE).

Jaggars, S. (2011). Online Learning: Does It Help Low-Income and Underprepared Students? (Assessment of Evidence Series). https://academiccommons.columbia.edu/doi/10.7916/D82R40WD.

Kong, Q. (2020). Practical exploration of home study guidance for students during the COVID19 pandemic: A case study of Hangzhou Liuxia Elementary School in Zhejiang Province, China. Science Insight Education Front, 5(2), 557-561.

Lee, J. C. K., Yin, H., \& Zhang, Z. (2010). Adaptation and analysis of Motivated Strategies for Learning Questionnaire in the Chinese setting. International Journal of Testing, 10(2), $149-165$.

Li, X., \& Chu, S. K. W. (2020). Exploring the effects of gamification pedagogy on children's reading: A mixed-method study on academic performance, reading-related mentality and behaviors, and sustainability. British Journal of Educational Technology, e13057.

Li, X., Yang, Y., Chu S.K.W., Zainuddin Z. \& Zhang Y. (2020) Applying blended synchronous teaching and learning for flexible learning in higher education: an action research study at a university in Hong Kong, Asia Pacific Journal of Education, 1-17. 
Llorens-Largo, F., Gallego-Durán, F. J., Villagrá-Arnedo, C. J., Compañ-Rosique, P., SatorreCuerda, R., \& Molina-Carmona, R. (2016). Gamification of the learning process: Lessons learned. IEEE Revista Iberoamericana de Tecnologias del Aprendizaje, 11(4), 227-234.

Mahoney, J. L. (2014). School extracurricular activity participation and early school dropout: A mixed-method study of the role of peer social networks. Journal of Educational and Developmental Psychology, 4(1), 143.

McAleer, M. (2020). Prevention is better than the cure: Risk management of COVID-19. Journal of Risk and Financial Management, 13, 46.

Newton, D. (2015, November 4). Cheating in online classes is now big business. The Atlantic. https://www.theatlantic.com/education/archive/2015/11/cheating-through-onlinecourses $/ 413770 /$.

$\mathrm{Ng}, \mathrm{T}$. K. (2021). New interpretation of extracurricular activities via social networking sites: A case study of artificial intelligence learning at a secondary school in Hong Kong. Journal of Education and Training Studies, 9(1), 49-60.

Ng, T. K., Reynolds, R., Chan, H. M. Y., Li, X. H., \& Chu, S. K. W. (2020). Business (teaching) as usual amid the COVID-19 pandemic: A case study of online teaching practice in Hong Kong. Journal of Information Technology Education: Research, 19, 775-802.

Özdener, N. (2018). Gamification for enhancing Web 2.0 based educational activities: The case of pre-service grade school teachers using educational Wiki pages. Telematics and Informatics, 35(3), 564-578. https://doi.org/10.1016/j.tele.2017.04.003.

Parsons, S., \& Sklar, E. (2004, March). Teaching AI using LEGO Mindstorms. In AAAI Spring Symposium.

Pintrich, P. R. (2004). A conceptual framework for assessing motivation and self-regulated learning in college students. Educational Psychology Review, 16(4), 385-407.

da Rocha Seixas, L., Gomes, A. S., \& de Melo Filho, I. J. (2016). Effectiveness of gamification in the engagement of students. Computers in Human Behavior, 58, 48-63. https://doi.org/10.1016/j.chb.2015.11.021.

Richardson, W. (2009). Blogs, wikis, podcasts, and other powerful web tools for classrooms. Thousand Oaks, CA: Corwin Press.

Shen, X. (2015, March 30). You can pay people to take online exams and classes for you in China. South China Morning Post. https://www.scmp.com/abacus/culture/article/3077487/you-can-pay-people-take-onlineexams-and-classes-you-china.

Stringer, E. T. (2008). Action research in education. Upper Saddle River, NJ: Pearson Prentice Hall.

Ståhlbröst, A., \& Bergvall-Kåreborn, B. (2011). Exploring users' motivation in innovation communities. International Journal of Entrepreneurship and Innovation Management, 14(4), 298-314. 
Szeto, E. (2015). Community of Inquiry as an instructional approach: What effects of teaching, social and cognitive presences are there in blended synchronous learning and teaching? Computers \& Education, 81, 191-201.

Thongmak, M. (2013). Social network system in classroom: antecedents of Edmodo@ adoption. Journal of E-learning and Higher Education, 2013(1), 1-15.

Thouin, É., Dupéré, V., Dion, E., McCabe, J., Denault, A. S., Archambault, I., ... \& Crosnoe, R. (2020). School-based extracurricular activity involvement and high school dropout among at-risk students: Consistency matters. Applied Developmental Science, 25(1), 114.

Williams, R., Park, H. W., Oh, L., \& Breazeal, C. (2019, July). Popbots: Designing an artificial intelligence curriculum for early childhood education. In Proceedings of the AAAI Conference on Artificial Intelligence, 33(1), 9729-9736.

Won, S. G., Evans, M. A., \& Huang, L. (2017). Engagement and knowledge building in an afterschool STEM Club: Analyzing youth and facilitator posting behavior on a social networking site. Learning, Media and Technology, 42(3), 331-356.

Vieno, A., Perkins, D. D., Smith, T. M., \& Santinello, M. (2005). Democratic school climate and sense of community in school: A multilevel analysis. American Journal of Community Psychology, 36(3-4), 327-341.

Yoon, D. M., \& Kim, K. J. (2015). Challenges and opportunities in game artificial intelligence education using Angry Birds. IEEE Access, 3(1), 793-804.

Zaff, J. F., Moore, K. A., Papillo, A. R., \& Williams, S. (2003). Implications of extracurricular activity participation during adolescence on positive outcomes. Journal of Adolescent Research, 18(6), 599-630.

Zainuddin, Z., Chu, S.K.W., Shujahat, M., \& Perera, C.J. (2020). The impact of gamification on learning and instruction: A systematic review of empirical evidence. Educational Research Review, 30, 100326. 


\section{Appendix: Survey Questions}

Motivational Questionnaire (Lee, Yin \& Zhang, 2010)

5-point Likert scale: (1) Strongly disagree, (2) Disagree, (3) Neutral, (4) Agree, (5) Strongly agree

Self-efficacy

1. Compared with other students in this after-school online course I expect to do well.

2. I'm certain I can understand the ideas taught in this course.

3. I expect to do very well in this online course.

4. Compared with other students in this course, I think I'm a good student.

5. I am sure I can do an excellent job on the problems and tasks assigned for this course.

6. I think I will receive a good grade in e-quizzes in this course.

7. My study skills are excellent compared with others in this course.

8. Compared with other students in this class, I think I know a great deal about the subject "Artificial Intelligence."

9. I know that I will be able to learn the online materials for this course.

Intrinsic value

1. I prefer online tasks that are challenging so I can learn new things.

2. It is important for me to learn what is being taught in this course.

3. I like what I am learning in this course.

4. I think I will be able to use what I learn in this course in other IT lessons.

5. Even when I do poorly on an e-quiz, I try to learn from my mistakes to give another try.

6. I think that what we are learning in this course is interesting.

7. I will learn something even if they require more online tasks.

8. I think that what we are learning in this course is interesting.

9. Understanding the subject "Artificial Intelligence" is important to me.

Learning strategies

1. When I do online tasks, I try to put together the information for class and from the materials in Edmodo.

2. When I do online tasks, I try to remember what the tutors said according to videos via Edmodo so I can answer the questions correctly.

3. It is hard for me to decide what the main ideas are in what I study in Edmodo.

4. When I study, I put important ideas into my own words.

5. I always try to understand what the tutors in the video are saying even if it is difficult/doesn't make sense.

6. When I study for online tasks, I try to remember as many facts as I can.

7. When studying, I copy my notes over to help me remember the material.

8. I use what I have learnt from old online tasks (in the previous phase) to do new online tasks.

9. When I am studying a unit of "Artificial Intelligence," I try to make everything fit together. 
10. When I read the material in Edmodo for this course, I say the words over and over to myself to help me remember.

11. I outline the chapters in Edmodo to help me study.

12. When reading the materials in Edmodo, I try to connect the things I am reading about to what I already know.

13. When I study for online tasks, I practice saying the important facts over and over to myself.

Self-regulation

1. I ask myself questions to make sure I know the materials I have been studying in Edmodo.

2. When work is hard, I either give up or study only some of the parts.

3. I work on practical tasks and e-quizzes more than once even when I don't have to.

4. Even when study materials are dull and uninteresting, I keep working until I finish.

5. Before I begin studying, I think about the things I will need to do to learn.

6. I often find that I have been attending the course but don't know what it is all about.

7. I find that when the tutors in Edmodo are talking, I think of other things and don't really listen to what is being said.

8. When I'm learning in the course, I stop once in a while and go over what I have read.

9. I work hard to get a good grade in the e-quizzes even when I don't like a class.

Overall satisfaction

To compare the traditional and blended ECA approach,

1. I think there are no learning differences between traditional and online ECA experiences.

2. I will recommend this course to classmates.

3. I hope that this format of ECA can be sustained after school resumes.

4. Overall, I enjoy having this blended ECA.

Polling questions

1. Which ECA settings do you prefer, traditional or blended after-school activities?

2. Do you think this blended course should be sustained after school resumes?

Other questions

1. Share your ideas about how to improve this course.

2. Share with me some of the learning challenges you encountered in the blended ECAs.

3. Why did you join this activity?

4. How would you improve this activity?

5. What features did you like on the Edmodo platform? 